Management, Procurement and Law Volume 168 Issue MP5

Using tacit knowledge in training and accident prevention

Aboagye-Nimo, Raiden, King and Tietze
Proceedings of the Institution of Civil Engineers

Management, Procurement and Law 168 October 2015 Issue MP5

Pages 232-240 http://dx.doi.org/10.1680/mpal.14.00027

Paper 1400027

Received 11/06/2014 Accepted 15/04/2015

Published online 25/08/2015

Keywords: education \& training/health \& safety/knowledge management i

ice

Institution of Civil Engineers

publishing

\title{
Using tacit knowledge in training and accident prevention
}

1 Emmanuel Aboagye-Nimo MSc, PhD

School of Environment and Technology, University of Brighton, Brighton, United Kingdom

2 Ani Raiden MSC, PhD

Nottingham Business School, Nottingham Trent University, Nottingham, United Kingdom
3 Andrew King $M A, P h D$

School of Architecture Design and the Built Environment, Nottingham Trent University, Nottingham, United Kingdom

4 Susanne Tietze MA, MBA, PhD

Keele Management School, Keele University, Staffordshire, United Kingdom
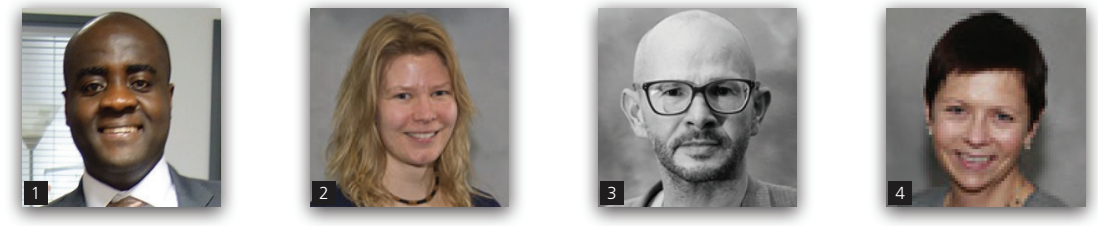

Tacit knowledge plays an invaluable role in construction and has been labelled as the 'most strategically important resource' in organisations. Microconstruction firms rely heavily on the tacit knowledge acquired by their workers when managing site safety. Unfortunately, the importance of this knowledge is sometimes overlooked due to its inexpressible and informal nature. This paper investigates how microconstruction firms use tacit knowledge to prevent accidents on site, thereby improving overall site safety. An ethnographic approach was used to gather rich in-depth qualitative data on the practices of these 'hard-to-reach' microconstruction firms. Five case studies were conducted in the East Midlands region of the UK. Findings from the case studies suggest that workers of microconstruction firms use tacit knowledge in areas such as training newcomers and also identifying and managing imminent risks and dangers on site. Additionally, tacit knowledge plays an important role in safety communications among the workers of these microfirms; it helps establish shared understanding and a common sense of achieving their goals. This research sheds light on an underexplored area of the construction industry, which is arguably crucial in preventing accidents and ensuring the well-being of site workers.

\section{Introduction}

Construction sites in the UK are known to be very dangerous compared to other workplaces in the country (Conchie and Burns, 2009; Wamuziri, 2006). Irrespective of size, construction firms adopt methods that help them prevent accidents and injuries on site (Gillen et al., 2004: p. 235). One specific accident prevention technique includes the effective use of personal protective equipment (PPE) (Lingard and Rowlinson, 2005). Broader approaches used to create and maintain positive safety cultures on site can be categorised as either formal (official procedures and policies) or informal (influenced by culture) (Koch, 2013: p. 699). The main differences between the safety management styles stem from the size of the organisation, learning and training methods, approach to managing risks and use of safety equipment (Gillen et al., 2004).

In the UK, microconstruction firms (employers of fewer than ten people) account for more than $90 \%$ of all employment in the construction industry (Federation of Small Businesses, 2013).
Research suggests that these microfirms use unorthodox approaches to employee development (informal training), which can easily be confused for 'no training' (UK Commission for Employment and Skills, 2012). Such informal approaches may have come about in response to resource poverty - for example, not having specific departments or groups of people responsible for training new workers, as is often done in large firms (HSE, 2010).

UK Health and Safety Executive (HSE) records show the steady decline in accidents from 2001 to 2010 in the East Midlands. Most significantly, the figures reveal that injuries that have kept workers out of work for more than 3 days ( +3 day injuries) have reduced from 10904 to 8049 over the 9 -year period. This represents a $26 \%$ reduction in the number of workplace accidents. Figures for major injuries and fatal injuries have also reduced: major injuries were down by $4 \%$ and fatal injuries were down by $61 \%$ (HSE, 2011). This trend of decline in accidents and injuries is still ongoing (HSE, 2014a). Although the HSE statistics on accidents and injuries do not report specifically on microconstruction firms, it has been found that 
more $82 \%$ of all reported health and safety injuries occur within small and medium-sized enterprises (SMEs) - that is, including microfirms (Arewa, 2014).

As microconstruction firms represent a large proportion of the industry, their practices play a significant role in the increase and decrease in accident and injury records. Owners of these microconstruction firms (who usually work as site operatives as well) have a considerable amount of influence on the overall culture of the firms: if the owner is very conscious about good health and safety practices, the other workers tend to follow suit due to the close interpersonal relationships they share (Hinze, 2004). The close interpersonal relationships among the workers of microconstruction firms also enable the workers to share 'hidden' knowledge and 'hidden' understanding (Aboagye-Nimo et al., 2012). Wamuziri (2013) stresses that shared beliefs and assumptions aid in strengthening safety cultures. Safety as a value is shared and internalised by everyone in the organisation (Wamuziri 2013).

As important as microconstruction firms are to the UK construction industry, their safety practices are understudied. This research investigated the microfirms' use of tacit knowledge in training of new workers and accident prevention on five construction sites in the East Midlands region of the UK. The importance of tacit knowledge in construction is not a new idea (Chen and Mohamed, 2009; Nesan, 2012). Nesan (2012: p. 56) highlights that it is this tacit knowledge that brings competence and skills to the individuals in construction and thus to the organisation as a whole. Chen and Mohamed (2009: p. 156) also found that tacit knowledge plays a strong and very important strategic role in helping organisations realise their long-term visions. However, understanding how tacit knowledge influences on-site training and accident prevention of site workers employed by microconstruction firms contributes to an emerging acknowledgement of the value informality plays in 'good practice'.

The next section discusses the concept of tacit knowledge and construction practices before consideration of safety training on site. An outline of the data collection methods follows together with discussion of the research findings. In the final section of this paper, the conclusion, the practical contribution of this study is highlighted.

\section{The concept of tacit knowledge and construction practices}

There is knowledge that can be explained and knowledge that cannot be explained. These are known as explicit knowledge and tacit knowledge, respectively (Egbu and Robinson, 2005).

Although knowledge can be classified in many and varied ways - for example, personal against shared and public; practical-theoretical, hard-soft; internal-external - the classification of tacit and explicit knowledge remains the most common (Pathirage et al., 2008). Tacit knowledge represents knowledge based on the experience of individuals, expressed in human actions in the form of evaluation, attitudes, points of view, commitments and motivation (Nonaka et al., 2000). In contrast, explicit knowledge is codifiable knowledge that is inherent in non-human storehouses, including organisational manuals, documents, and databases (Pathirage et al., 2008). Unlike explicit knowledge, tacit knowledge varies from person to person: when a teacher delivers a speech, two students build knowledge according to their own attitudes, intelligence and previous knowledge, even though the transmission by the teacher is the same for the two of them. Thus, the knowledge produced is different (Pathirage et al., 2008).

In the construction industry, just like in any other setting, formal education equips individuals with explicit knowledge (Bartholomew, 2008). The knowledge they need to become effective professionals or tradesmen comes later from practice, and this falls under the tacit aspect of knowledge (Bartholomew, 2008). Polanyi (1966) made reference to tacit knowing as a process rather than a form of knowledge and stressed the importance of beliefs, habits and culture that play significant roles in an individual's capability without their being conscious of them. 'Tacitness' is a matter of degree, and 'we all know more that we can tell' (Bartholomew, 2008: p. 22). A significant amount of what is known stems from learning and experience that is rooted in specific contexts, and includes paradigms, viewpoints and beliefs as well as intellectual and performance skills (Bartholomew, 2008).

The explicit knowledge that is found in organisations (e.g. procedure manuals) is dwarfed when compared to the tacit knowledge hidden in the heads of individual workers (Bartholomew, 2008). Through questions and instant chat tools such as conversations, some of this tacit knowledge is readily available, but there is more that cannot be explained without difficulty or sometimes cannot be explained at all (Haider, 2009). The information of highest value (that is, highest levels of expertise) is deeply tacit, unconscious and invariably impossible to articulate (Bartholomew, 2008; Lam, 2000). Knowledge possessed collectively by a group is thus very valuable to the team (Suresh and Egbu, 2007), for example in managing risks.

As shown in Figure 1, the competitive value of knowledge increases with depth of the iceberg, hence from explicit knowledge to conscious tacit knowledge and then followed by unconscious tacit knowledge. Comparing organisations' knowledge resources to an iceberg, it can be gathered that the explicit knowledge - that is, the visible top of the iceberg - is easy to find and recognise. However, the invisible and hard-to-express part forms the bulk of knowledge within organisations; this is the hidden and tacit knowledge resources (Pathirage et al., 2007). It is the unarticulated knowledge that resides in human beings, which is obtained by internal individual processes like experience, reflection, internalisation, or individual talents. For example, workers within the construction industry are not in a position to 'cut and paste' effective practices (explicit knowledge) from the past due to the unique and complex nature of each construction project, and for this reason they tap into their hidden tacit knowledge. As such, researchers attempting to understand this concept will require methods that allow for the 


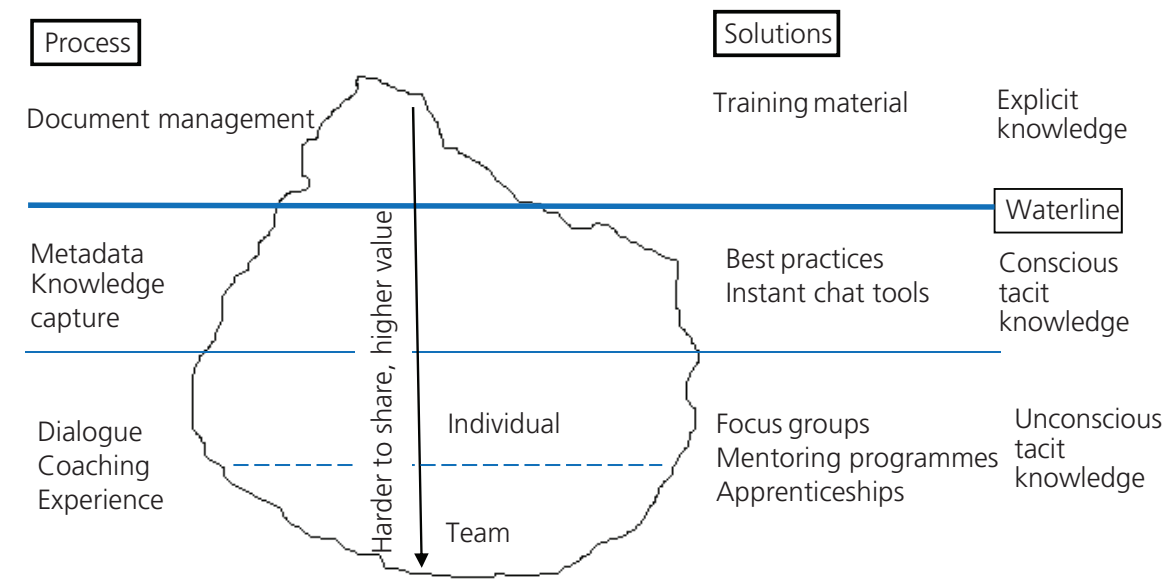

Figure 1. The knowledge iceberg adapted for construction

(adapted from Haider, 2009: p. 78)

collection of deep qualitative data in order to understand the participants extensively, including their backgrounds and attitudes.

People gain more experience in a given field as they learn more and subsequently become more competent before eventually becoming experts (Baarts, 2009; Gillen, 2010; Torner and Pousette, 2009). In construction, experts and experienced workers have observed and practised for long enough to know about different situations and, as such, can anticipate and thus manage looming dangers on site (Baarts, 2009). These practices become second nature for the experienced workers as the knowledge is internalised and the skills subsequently become tacit.

Experts are different from novices because the experts

- possess vastly more knowledge of all kinds, including examples, general laws, physical skills and specialised language, as a result of years of experience and thinking about their field, and this is more richly interlinked and understood in terms of higher-level concepts

notice patterns in situations and problems that novices miss; ignore irrelevancies; focus on key issues; have generally accurate intuitions; and deploy the most relevant concepts, parallels and tools

- make extensive use of long-term memory, recalling key knowledge automatically and without conscious effort (Bartholomew, 2008: p. 21).

Workers can also learn from mistakes. Knowledge-based mistakes are likely to occur within highly homogeneous groups (Teo and Loosemore, 2001). Microconstruction firms fall into the highly homogeneous group category as they are known for their closeness and unison.

Experienced workers pass local knowledge to less experienced workers in the form of on-site training.

\section{Safety training on site}

While training of workers can take different forms, workers usually prefer and carry out training exercises through demonstration and practice (Gherardi and Nicolini, 2002). This is also referred to as onthe-job training (Gherardi and Nicolini, 2002). Much of the knowledge taught on site is deeply tacit and can only be absorbed incrementally and slowly; furthermore, it is most easily acquired through one-to-one interaction, which can be tailored to suit the learner's individual knowledge needs and their pace of learning (Bartholomew, 2008: p. 120).

In the construction industry, there is a strong link between safety training and a reduction of injuries and accidents, and safer practices for that matter (Lingard and Holmes, 2001). Besides training workers on how to undertake their tasks safely, training of workers on how to use PPE and other safety kit effectively makes a crucial impact on safety performance on sites (Langford et al., 2000; Sawacha et al., 1999). A lack of this local knowledge can result in unsafe conditions for workers and their colleagues (Hari et al., 2005; Sawacha et al., 1999).

Construction work, just like many occupations, requires personnel to be trained in order for activities to be carried out effectively and successfully. Communication is the most important aspect of construction training and construction safety (Emmitt and Gorse, 2003; HSE, 1999; Styhre, 2009). As alluded to earlier, microconstruction firms often make use of unorthodox methods that can easily be misinterpreted as 'no training at all'. They tend to adopt a 'hands on' approach to health and safety training - that is, training workers solely on the site as opposed to employing formalised training techniques (Vassie et al., 2000).

\subsection{Explicit against tacit knowledge gained by way of on-site on-the-job training}

In relation to the safety of workers on construction sites, the UK Construction (Design and Management) Regulations 2007 (HMG, 
2007; HSE, 2014b) require workers to be able to demonstrate their 'competence' in being able to work safely and therefore not causing harm or danger to themselves or others. One of the major site requirements in the UK is the Construction Skills Certification Scheme (CSCS) card. Possession of this card signifies that the holder has passed the construction scheme health and safety test (HSE, 2014b), an indication of competence in safety. Competence is when an individual possesses

- sufficient knowledge of the tasks to be undertaken and the risks involved

v the experience and ability to carry out their duties in relation to the project

- the ability to recognise their limitations and take appropriate action to prevent harm to those carrying out construction work or those affected by the work (HSE, 2014b).

The qualities required for an individual to demonstrate competence are focused on the person's knowledge and experience (HSE, 2014b). It can therefore be argued that workers with more experience and greater ability to carry out their duties safely have a higher level of competence than those with less experience. Furthermore, using the CSCS card or its equivalent as the most effective way of judging workers' knowledge on safety can be disputed as the test may not be able to replicate site conditions accurately.

The CSCS card is the industry's largest scheme, covering numerous occupations, including trades, technical, supervisory and management (HSE, 2011). However, there are issues relating to such government skills and training initiatives as they have been found to involve uncertainty around their value and relevance (Abdel-Wahab et al., 2008: p. 117). For example, even though programmes including the CSCS scheme are intuitively appealing to SMEs, their value as a mechanism for improving skill remains questionable (Dainty et al., 2005). Furthermore, workers of small firms and microfirms question the relevance of government training initiatives to employer's needs as well as the lack of information about the nature of such schemes and their potential benefits to employers (Kitching and Blackburn, 2007). Such formal training schemes are based on explicit knowledge, whereas these microfirms rely mainly on their informal and tacit knowledge among their workers.

As this research focuses of training and accident prevention, behaviours of workers will be observed to find out whether they possess some or all of the above characteristics. For example, the investigation will examine whether tacit knowledge plays an effective role when training new workers on site.

\section{Methods}

Five case studies were conducted as the project intended to interpret the social world of construction site activities through a first-hand observational study (Saunders et al., 2009: p. 591). This approach allowed for a better understanding of the sociological processes (e.g. work practices and worker interactions) of the groups being studied (O'Riain, 2009; Tutt et al., 2013). The case study approach was suitable for this research project in terms of addressing the aims: to study and highlight how microfirms use tacit knowledge to prevent accidents on construction sites.

In-depth interviews and non-participant observations were carried out on five construction sites (see Table 1 for details of sites visited). Research participants included the owners and the workers of the companies, thus helping the research acquire different perspectives on effective approaches to site training and accident preventive methods. The different trades and sites included in the study offered a broader understanding of the behaviours and attitudes of workers of different firms.

The two methods employed in the collection of data helped acquire rich and in-depth information on the approaches adopted for site training and how workers of microconstruction firms prevent accidents (Haigh, 2008). Data collection was carried out on all five construction sites with great care and the aim of minimal researcher influence. The observation was meant to reveal hidden or unconscious practices that may not have been discovered or mentioned during the interviews or alternatively practices that cannot be uncovered through the use of tools such as questionnaires (Proverbs and Gameson, 2008). Interview lengths varied considerably, with an average of about $45 \mathrm{~min}$. A digital voice recorder was used to record the interviews on the interviewees' approval. Interview locations were selected spontaneously. These included site manager's offices, site canteens, workers' smoking area, on top of stacked blocks and even while sitting on a half-built brick wall. Field notes were used to collect observed data. In relation to observations, although the study was focusing on some specific microconstruction firms, the fluid nature of sites meant that the workers' interactions with other workers from different firms would also be noticed. This is an important point because some of the microfirms being studied worked as subcontractors on large projects on a regular basis. For this reason, general consent for observing workers was always obtained from site managers. Site visits to the various microfirms were carried out over a week at a time, and then follow-up visits were carried out after 3 months.

Microfirms fall within a category described by the HSE as the "hardto-reach' group (Willbourn, 2009) and, as such, access to research participants was negotiated through gatekeepers trusted by these firms. Negotiations for access to microconstruction firms in the East Midlands region were conducted through personal contacts and a local safety group: Nottinghamshire Occupational Safety and Health Association.

Analysis of the data was conducted starting with a thorough thematic coding of the information (transcribed interview data and field notes from observations) using QSR NVivo 9.

\section{Findings and analysis}

Table 1 presents a summary of the sites included in the five case studies. 


\begin{tabular}{|c|c|c|c|c|c|}
\hline & $\begin{array}{l}\text { Nature of the } \\
\text { project/work }\end{array}$ & Site activities & $\begin{array}{l}\text { Workers on } \\
\text { site }\end{array}$ & $\begin{array}{l}\text { Key participants } \\
\text { presented in study }\end{array}$ & Noteworthy observations \\
\hline $\begin{array}{l}\text { Case study } 1 \\
\text { (Pilot) }\end{array}$ & $\begin{array}{l}\text { Refurbishment } \\
\text { of existing } \\
\text { structure }\end{array}$ & $\begin{array}{l}\text { Electrical, plumbing, } \\
\text { brickworks, screeding, } \\
\text { fit-out works }\end{array}$ & 15 & $\begin{array}{l}\text { Rick - skilled labourer } \\
\text { Mark - labourer } \\
\text { John - owner }\end{array}$ & $\begin{array}{l}\text { Interpersonal interactions, } \\
\text { non-verbal } \\
\text { communications }\end{array}$ \\
\hline Case study 2 & $\begin{array}{l}\text { Preparation for } \\
\text { new builds }\end{array}$ & $\begin{array}{l}\text { Trench digging, } \\
\text { excavation, roofing, } \\
\text { plumbing, building } \\
\text { envelopes }\end{array}$ & 30 & $\begin{array}{l}\text { Jim - machine } \\
\text { operator }\end{array}$ & $\begin{array}{l}\text { Risk assessment methods, } \\
\text { brainstorming and } \\
\text { decision making }\end{array}$ \\
\hline Case study 3 & New building & Frame and ground works & 19 & $\begin{array}{l}\text { George - bricklayer } \\
\text { Scott - owner } \\
\text { Steve - bricklayer }\end{array}$ & $\begin{array}{l}\text { Leadership techniques, } \\
\text { organisational culture }\end{array}$ \\
\hline Case study 4 & $\begin{array}{l}\text { Preparation and } \\
\text { laying } \\
\text { foundation for } \\
\text { new housing } \\
\text { community }\end{array}$ & $\begin{array}{l}\text { Clearing ground, } \\
\text { reinforcing foundations, } \\
\text { building envelopes }\end{array}$ & 15 & $\begin{array}{l}\text { Mickey - } \\
\text { groundworker }\end{array}$ & $\begin{array}{l}\text { Supportive setting, } \\
\text { informal risk assessment, } \\
\text { close worker relationships }\end{array}$ \\
\hline Case study 5 & $\begin{array}{l}\text { Completing } \\
\text { new building }\end{array}$ & $\begin{array}{l}\text { Completing pavement } \\
\text { and landscaping, external } \\
\text { decoration, final clean-up }\end{array}$ & 6 & Andy - skilled labourer & $\begin{array}{l}\text { Role model leadership, } \\
\text { genuine safety concerns } \\
\text { for workers, verbal } \\
\text { communication }\end{array}$ \\
\hline
\end{tabular}

Table 1. Profile of case studies

The key participants that are presented in the findings and their job roles are as follows: Rick (case study 1 - skilled labourer), Jim (case study 2 - groundworker), Tom (case study 5 - owner), Ben (case study 1 - labourer), Andy (case study 5 - skilled labourer), George (case study 3 - bricklayer), Derek (case study 3 - owner), Steve (case study 3 - bricklayer), Tony (case study 4 - groundworker) and John (case study 1 - owner/joiner). The above were chosen as key participants for this paper due to their extensive experience in the construction industry and their views towards knowledge management and site safety. It is noted that there were less experienced workers on the sites, but the aim of this study is to promote accident prevention and effective site training methods among workers of microfirms; thus, emphasis is placed on the findings from the more experienced and conscientious workers. A PPE inspection was carried out as part of site investigations. This was done to ensure that the lack of use of PPE for certain tasks (among workers of microfirms) was not done out of lack of safety gear. It was confirmed that all the firms had enough PPE in good working condition to cover all the workers. Tacit knowledge was identified to be an integral concept in all the themes presented in this paper, namely on-the-job training, learning from mistakes and, more importantly, accident prevention on site.

\subsection{On-the-job training}

Training and learning can come in many settings or forms. According to the interviewees, there was the classroom-type setting and the training that occurred on site. As much as respondents said they saw the relevance of training in a 'classroom-based' setting, they all insisted that the process could not be compared to training received from the job and what could be learnt through experience. Some respondents stated the following about effective training

'I don't think you can replicate anything in the classroom that happens on site. I think you can only be made aware of risks in the classroom' (John).

'You have someone telling you in an office what's safe and what's not doesn't really work for me. [Training] needs to be on the site form so they can show you' (Tom).

It can be deduced from such comments that the workers are all in support of training on site. John states that construction training cannot be replicated because classroom settings cannot simulate the actual conditions on site even if it is the practical aspect of the training - for example, workshop and laboratory sessions. Sillitoe (2002) confirms that the effective way of transferring local knowledge, such as technical know-how, working practices and even the values of workers, is best undertaken through actual work activities.

Some participants explained that there were benefits of classroomtype learning as it makes workers aware and gives them answers to 'some' questions. However, this approach cannot offer the required experience. Numerous experienced workers mentioned that they preferred to demonstrate to the new workers and then watch them repeat the process in their presence. By watching the new worker perform the task, the experienced worker has ensured that the demonstration was effective and the learning process has also been 
successful. This serves as a form of feedback process. According to Gherardi and Nicolini (2002), when workers observe relevant instances and commit them to memory and subsequently compare them to other situations, they draw their own conclusions and this influences future performances, hence creating a more effective learning experience. This process of effectively supervising new and less experienced workers by more knowledgeable and experienced workers is known as mentoring (Bartholomew, 2008). The procedure also serves as a quality assurance technique that ensures the knowledge of the newer workers is of the right substance, hence preventing unwanted circumstances such as injuries and accidents.

John pointed out that the current requirements for people to get on construction sites, including the CSCS card (which is a classroombased test for construction workers), was instead creating unsafe site situations as new workers on sites did not know enough with respect to accident prevention even though they had passed the test. He further explained that obtaining the certificate was easy. He explained that he passed his test in about 'four minutes', emphasising that this is not because he is smart but because the questions were 'ridiculously easy'. Tom also expressed his grievance by stating the following

'I think when you chuck 'em on a site and give them a CSCS card and say that's it, you can work on a site and where they read a book and go on a test that takes them 10 minutes to pass, I think the test should be a lot harder. A lot harder!' (Tom).

The term 'chuck' as used by Tom shows some resentment towards the kind of skill he believes these new workers possess even after they have successfully acquired the CSCS card. Even though Tom and John stress that the test is easy, this lack of difficulty they mention can be attributed to the fact that they have been on construction sites for a long period and hence acquired unconscious (tacit) knowledge. In support of John and Tom's point, Ben added that since starting his work in construction, his knowledge had grown, and he is now more aware of his surroundings and what could go wrong as well as how to prevent accidents. Ben is not able to describe specifically the knowledge he has acquired, thus implying tacit knowledge. This confirms findings that workers of small firms and microfirms do not support the CSCS programme (Dainty et al., 2005). Interestingly, all the workers of the microfirms included in this study had CSCS cards. The owners explained that the main reason for having CSCS cards was because it was a prerequisite for working on larger projects and sites.

Although the new workers had CSCS cards, workers believed the guidance on site was critical to their success in the workplace. George and Andy, being among the most experienced workers on their sites, both discussed what they believe people should instinctively know and do. Expecting or assuming people know or understand issues can be extremely dangerous, especially when issues of potentially fatal consequences are involved, such as in construction work (Bartholomew, 2008). Leaving safety matters to newcomers (without guidance) can result in new workers picking up wrong attitudes and unsafe practices that can eventually lead to the occurrence of accidents to themselves and workmates (Gherardi and Nicolini, 2002). Steve explained that even though he refers to something as common sense, he believes training and guidance cannot be excluded. He states

'...you've got to keep an eye on [the newcomer] until you know he's alright to himself' (Steve).

From this statement, Steve shows that there is a point where a teacher or trainer notices that the newcomer is capable of working individually.

Steve discussed common sense as though it were obvious, but his other statement shows that common sense is not straightforward (explicit) and thus guidance from more experienced workers is required. As such, it can be argued that the common sense in site safety is a hidden form of knowledge, an indication that it is tacit knowledge.

\subsection{Learning from mistakes}

According to the workers, individuals can learn from their own mistakes as well as the mistakes of others. Ben states the following: '... on-site training ... you know what you've done wrong'.

Gherardi and Nicolini (2002) also observed that workers believe that when people observe mistakes and near misses, they end up committing the details of the given incident to memory and hence learn from it. The more experienced workers all clearly highlighted that they have come across several mistakes in their careers. They also admit that they were responsible for some of these mistakes, and they witnessed others. Participants stated the following

'I think I've seen enough. My experience, I've been on site. I've seen things done well, done safely and I've seen things go wrong, so obviously my experience has influenced how I work' (John).

'When you've seen someone else misbehave or how you've worked based on how far out you've worked it's just experience ... you've got to be on site and you've got to be doing the job and pick it up; the right ways as well as the wrong ways' (Derek).

John added that he used to pick up heavy objects using wrong techniques (going against advice given to him when he was a new worker), and this had now given him back problems, so he was now 'passing [his] message back to [his] guys'. Other respondents also pointed out that even a near miss is enough to teach a worker about potential hazards and risks that are readily available in the construction industry

'Sometimes you see near misses and that sort of thing, you know, and you learn from it' (Jim).

Derek vividly described his friend's accident from another project that he heard of. His friend's excavator fell into a cellar while 
working on a project. For this reason, Derek and his team have made it a point to check sites thoroughly for cellars before they start any ground works, irrespective of what site plans or drawings may say. Bartholomew (2008) reveals that mistakes and near misses can serve as painful yet very effective learning experiences for workers.

\subsection{The role of tacit knowledge in worker accident prevention}

Both tacit and explicit knowledge are used on site. Tom suggests: 'For a beginner, obviously he has to be trained [in theory] and then he comes to the site to pick up the practical side of it and he's got to be under someone's guidance all the time'. He acknowledges the place for the explicit knowledge as theory, but adds that the practical side needs to be 'picked up' and not learnt or trained as he described the theory process. Haider (2009) categorises the knowing of these practical aspects of work as mainly tacit as workers are not able to teach it explicitly but can demonstrate it for the new workers to learn.

A key statement made (regarding tacit knowledge) by an experienced worker was the following

'Experience told you they're not safe. Somebody new on site might not see them' (Rick).

From Rick's statement, it is noticed that he taps into his tacit knowledge, as he states that 'experience told you they're not safe'. $\mathrm{He}$ is, however, unable to explain how this experience informed his decision. This is one of the inexplicable characteristics of tacit knowledge (Davenport and Prusak, 1998). Participants also discussed how their awareness for safe and unsafe work conditions had improved considerably after practising on site. 'Awareness' is not an explicit trait that one acquires, as it is more of an implicit quality (McInerney, 2002).

A setting for explicit knowledge against tacit knowledge is evident. Several respondents highlight the importance of tacit knowledge in learning safe work practices. Considering how experienced workers like John and Tony found the CSCS test easy and Ben, a newer worker, also believed that he 'only' learnt the practical and important aspects of accident prevention on site, it comes as no surprise that Dainty et al. (2005) found that workers believe schemes (including CSCS) are irrelevant to actual safety matters and therefore are only set up for bureaucracy.

One unique observation made on site with regards to workers using tacit knowledge in accident prevention occurred when two of John's workers (Martin and Glen) were carrying a movable scaffold and were coming up to a cable, creating a trip hazard. Martin was in clear view of the cable, and he looked down to the cable and then looked back up at Glen. Glen then instinctively looked where Martin had looked earlier and noticed the cable and subsequently avoided it. Had the workers not shared some common knowledge, Glen would not have understood the little implicit gesture made by Martin. A worker who does not share this common tacit understanding with other workers would need to be informed explicitly. Thus, body language and other actions also play a major role in communicating effectively in difficult situations, whereby explicit methods like direct verbal communication may be constrained, such as excessively noisy environments. Uher and Loosemore (2004) clarify that the type of communication undertaken by Glen and Martin requires a common understanding among the workers. If Glen and Martin did not have this common understanding to such gestures, Glen could have suffered as a result of the trip hazard. This finding is also in line with the explanation of Pathirage et al. (2008) on how different people without shared backgrounds or attitudes will understand information differently.

Tacit knowledge about the different types of construction and associated processes provides an underlying ability to choose between generic physical approaches to safety systems (Forsythe, 2014: p. 242). This idea is clearly applicable to the use of tacit knowledge in accident prevention, especially when looking closely at the empirical findings of this study. In this case, the generic approaches will include explicit 'broad-brush' measures like competence schemes, such as the use of CSCS cards, while the use of tacit knowledge can help individuals apply much-needed situational knowledge that can help workers avoid accidents and injuries on site.

\section{Conclusions}

In this paper, the use of tacit knowledge in on-site training and accident prevention among workers of microconstruction firms has been presented. Data were collected using semi-structured interviews and non-participant observations to acquire rich qualitative data. The key findings show that the small sizes and interpersonal relationships play a significant role in the way knowledge is passed on in microconstruction firms, aiding workers' understanding of each other and increasing shared safety values.

Findings of the study have shown that due to the 'tacitness' of the knowledge that workers acquire from years of experience on site, its importance can be overlooked. This leads to the knowledge being referred to as simply 'experience'. In addition, workers of microconstruction firms acknowledge the role of formal and explicit knowledge in site practices but strongly criticise the use of such knowledge as the yardstick for safety competence. An important assertion that needs to be made is that tacit knowledge cannot be captured and shared as done with explicit knowledge. However, the flow of tacit knowledge can be developed with time and experience through training. More importantly, through practices such as 'mentoring' (usually informally in microfirms), new and less experienced workers are able to work under the close supervision of experienced and conscientious workers in order to appreciate, understand and share common safety goals. This is an effective way of sharing tacit knowledge as the experienced workers are able to check and ensure that the knowledge passed on to new workers has been assimilated unambiguously. In addition, workers 
can try and share it by demonstrating good safety practice on site, for example, and in interactions with individuals who are learning by doing/observing them.

Further research into tacit knowledge and accident prevention is currently underway to compare and contrast between the different practices adopted by larger organisations and microfirms. This will create better understanding of informal site practices, especially in relation to accident prevention.

\section{Practical contributions of the study}

This research was conducted with microconstruction firms based in the East Midlands, and for this reason, the research offers indepth information on specific site training and accident prevention techniques employed by workers of microconstruction firms in the area. Also, this is being thought of as the first research in the region using in-depth and rich qualitative work to investigate the use of tacit knowledge in improving site safety. It is hoped that dissemination of the findings will encourage other microfirms of the region and other areas to help workers prevent injuries and accidents on site.

\section{Acknowledgements}

The authors would like to acknowledge members of Nottinghamshire Occupational Safety and Health Association for facilitating access to the construction sites.

\section{REFERENCES}

Abdel-Wahab MS, Dainty ARJ and Ison SG (2008) The participation of small-to-medium enterprises in skills and training initiatives in the UK construction industry: implications for skills policy and construction companies. Construction Information Quarterly 10(3): 116-121.

Aboagye-Nimo E, Raiden A, Tietze S and King A (2012) The use of experience and situated knowledge in ensuring safety among workers of small construction firms. In Proceedings of the 28th Annual ARCOM Conference (Smith SD (ed.)). Association of Researchers in Construction Management, Edinburgh, UK, pp. 413-422.

Arewa AO (2014) An Evaluation of Construction SMEs' Safety Performance and Company's Profitability. UK Commission for Employment and Skills, The Building Futures Group, London, UK.

Baarts C (2009) Collective individualism: the informal and emergent dynamics of practising safety in a high-risk work environment. Construction Management and Economics 27(10): 949-957.

Bartholomew D (2008) Building on Knowledge: Developing Expertise, Creativity and Intellectual Capital in the Construction Professions. Blackwell Publishing, Oxford, UK. Chen L and Mohamed S (2009) The strategic importance of tacit knowledge management activities in construction. Construction Innovation 10(2): 138-163.

Conchie S and Burns C (2009) Improving occupational safety: using a trusted information source to communicate risk. Journal of Risk Research 12(1): 13-25.
Dainty ARJ, Ison SG and Briscoe GH (2005) The construction labour market crisis: the perspective of small-medium-sized firms. Construction Management and Economics 23(4): 387-398.

Davenport TH and Prusak L (1998) Working Knowledge: How Organisations Manage What they Know. Harvard Business School Press, Boston, MA, USA.

Egbu CO and Robinson HS (2005) Construction as a knowledgebased industry in knowledge management in construction. In Management of Knowledge in Project Environments (Anumba CJ, Egbu CO and Carrillo P (eds)). Blackwell Publishing, Oxford, UK.

Emmitt S and Gorse C (2003) Construction Communication. Blackwell Science, Oxford, UK.

Federation of Small Businesses (2013) Small Business Statistics. Federation of Small Businesses, Blackpool, UK. See http:// www.fsb.org.uk/stats (accessed 01/06/2014).

Forsythe P (2014) Proactive construction safety systems and the human factor. Proceedings of the Institution of Civil Engineers Management, Procurement and Law 167(5): 242-252, http://dx. doi.org/10.1680/mpal.13.00055.

Gherardi S and Nicolini D (2002) Learning the trade: a culture of safety in practice. Organisation 9(2): 191-223.

Gillen M (2010) The NIOSH construction program: research to practice, impact, and developing a National Construction Agenda. Journal of Safety Research 41(3): 289-299.

Gillen M, Kools S, Sum J, McCall C and Moulden K (2004) Construction workers' perceptions of management safety practices: a qualitative investigation. Work 23(3): 245-256.

Haider S (2009) The organizational knowledge iceberg: an empirical investigation. Knowledge and Process Management 16(2): 74-84.

Haigh R (2008) Interviews: a negotiated partnership. In Advanced Research Methods in the Built Environment (Knight A and Ruddock L (eds)). Blackwell Publishing, Oxford, UK, pp. 111-121.

Hari S, Egbu C and Kumar B (2005) A knowledge capture awareness tool: an empirical study on small and medium enterprises in the construction industry. Engineering Construction and Architectural Management 12(6): 533-567.

Hinze J (2004) Construction Planning and Scheduling, 2nd edn. Prentice-Hall, Englewood Cliffs, NJ, USA.

HMG (Her Majesty's Government) (2007) Health and Safety. The Construction (Design and Management) Regulations 2007. The Stationery Office, London, UK, Statutory Instrument 2007 No. 320 .

HSE (Health and Safety Executive) (1999) Reducing Error and Influencing Behaviour. HSE, Norwich, UK, HSG48.

HSE (2010) Safety Initiative Targets Region's Small Construction Sites. HSE, Norwich, UK. See http://www.hse.gov.uk/press/ 2010/coi-nw-14constructionsafety.htm (accessed 30/03/2013).

HSE (2011) A Commentary on Routes to Competence in the Construction Sector. HSE, Harrogate, UK, research report RR877. HSE (2014a) Statistics on Fatal Injuries in the Workplace in Great Britain. Health and Safety Executive, London, UK.

HSE (2014b) Competence: Construction (Design and Management) Regulations 2007. HSE, Bootle, UK. See http://www.hse.gov. $\mathrm{uk} /$ construction/cdm/faq/competence.htm (accessed 30/06/2014). 
Kitching J and Blackburn R (2007) The Nature of Training and Motivation to Train in Small Firms. Department for Education and Skills, London, UK, research report RR330.

Koch C (2013) From crew to country? Local and national construction safety cultures in Denmark. Construction Management and Economics 31(6): 691-703.

Lam A (2000) Tacit knowledge, organisational learning and societal institutions: an integrated framework. Organisation Studies 21(3): 487-513.

Langford D, Rowlinson S and Sawacha E (2000) Safety behaviour and safety management: its influence on the attitudes of workers in the UK construction industry. Engineering Construction and Architectural Management 7(2): 133-140.

Lingard $\mathrm{H}$ and Holmes N (2001) Understandings of occupational health and safety risk control in small business construction firms: barriers to implementing technological controls. Construction Management and Economics 19(2): 217-226.

Lingard H and Rowlinson S (2005) Occupational Health and Safety in Construction Project Management. Taylor and Francis, Oxford, UK.

McInerney C (2002) Knowledge management and the dynamic nature of knowledge. Journal of the Association for Information Science and Technology 53(12): 1009-1018.

Nesan J (2012) Factors influencing tacit knowledge in construction. Australasian Journal of Construction Economics and Building 5(1): 48-57.

Nonaka I, Konno N and Toyama R (2000) Emergence of Ba. In Knowledge Emergence: Social, Technical and Evolutionary Dimensions of Knowledge Creation (Nonaka I and Nishiguchi T (eds)). Oxford University Press, Oxford, UK.

O'Riain S (2009) Extending the ethnographic case study. In The SAGE Handbook of Case-Based Methods (Byrne D and Ragin C (eds)). Sage, London, UK, pp. 289-306.

Pathirage CP, Amaratunga JG and Haigh RP (2007) Tacit knowledge and organisational performance: construction industry perspective. Journal of Knowledge Management 11(1): 115-126.

Pathirage CP, Amaratunga JG and Haigh RP (2008) Tacit knowledge generation and utilisation in the construction industry: from process perspective. Proceedings of the RICS Construction and Building Research Conference (COBRA 2008), Dublin, Ireland.

Polanyi M (1966) The Tacit Dimension. Routledge and Kegan Paul, London, UK.

Proverbs D and Gameson R (2008) Case study research. In Advanced Research Methods in the Built Environment (Knight A and Ruddock L (eds)). Blackwell Publishing, Oxford, UK, pp. 99-110.

Saunders M, Lewis P and Thornhill A (2009) Research Methods for Business Students, 5th edn. Pearson Education, Harlow, UK.

Sawacha E, Naoum S and Fong D (1999) Factors affecting safety performance on construction sites. International Journal of Project Management 17(5): 309-315.

Sillitoe P (2002) Participant observation to participatory development. In Participating in Development: Approaches to Indigenous Knowledge (Sillitoe P, Bicker A and Pottier J (eds)). Routledge, London, UK, pp. 1-23.
Styhre A (2009) Managing Knowledge in the Construction Industry: The Cases of Construction Work and Architecture. Taylor \& Francis/Spon Press, London, UK.

Suresh S and Egbu C (2007) The role of knowledge capture for improved competitiveness in small and medium enterprises in the UK construction industry: an empirical study. In Information and Knowledge Management - Helping the Practitioner in Planning and Building (Lima CP and Bauer M (eds)). Fraunhofer IRB Verlag, Stuttgart, Germany, pp. 194-203.

Teo M and Loosemore M (2001) A theory of waste behaviour in the construction industry. Construction Management and Economics 19(7): 741-751.

Torner M and Pousette A (2009) Safety in construction - a comprehensive description of the characteristics of high safety standards in construction work, from the combined perspective of supervisors and experienced workers. Journal of Safety Research 40(6): 399-409.

Tutt D, Pink S, Dainty ARJ and Gibb A (2013) 'In the air' and below the horizon: migrant workers in UK construction and the practice-based nature of learning and communicating OHS. Construction Management and Economics 31(6): 515-527.

Uher T and Loosemore M (2004) Essentials of Construction Project Management. UNSW Press, Sydney, Australia.

UK Commission for Employment and Skills (2012) UK Commission's for Employment and Skills Survey 2011: England Results. UKCES, Wath-upon-Dearne, UK.

Vassie L, Tomas J and Oliver A (2000) Health and safety management in UK and Spanish SMEs: a comparative study. Journal of Safety Research 31(1): 35-43.

Wamuziri S (2006) Safety culture in the construction industry. Proceedings of the Institution of Civil Engineers - Municipal Engineer 159(3): 167-174.

Wamuziri S (2013) Factors that influence safety culture in construction. Proceedings of the Institution of Civil Engineers Management, Procurement and Law 166(5): 219-231, http://dx. doi.org/10.1680/mpal.12.00023.

Willbourn C (2009) Report of Qualitative Research amongst 'Hard to Reach' Small Construction Site Operators. Health and Safety Executive, London, UK.

\section{WHAT DO YOU THINK?}

To discuss this paper, please submit up to 500 words to the editor at journals@ice.org.uk. Your contribution will be forwarded to the author(s) for a reply and, if considered appropriate by the editorial panel, will be published as a discussion in a future issue of the journal.

Proceedings journals rely entirely on contributions sent in by civil engineering professionals, academics and students. Papers should be 2000-5000 words long (briefing papers should be 1000-2000 words long), with adequate illustrations and references. You can submit your paper online via www.icevirtuallibrary.com/content/journals, where you will also find detailed author guidelines. 